\title{
Taking a Leadership Position In The IT Business Environment
}

\author{
Gregory W. Ulferts, (Email: ulfertgw@udmercy.edu), University of Detroit Mercy
}

Terry L. Howard, University of Detroit Mercy

Ryan C. Ulferts, University of Detroit Mercy

\section{INTRODUCTION}

ell-defined Industrial economics have been based upon internal, specialized, and proprietary business
models. Success in that economy has been dependent upon the ability to produce and distribute
products and services faster, better, and cheaper than competitors (Economy of Scale). The opportunity for such competition translates into executable capabilities primarily by building specialized plants, jobs, and workers that support that opportunity. Then, and only then, an Economy of Scope will develop when those capabilities have been established. The business value is heavily dependent upon that ability to leverage an existing business infrastructure with a launch of a new opportunity. Job specialization, hierarchical supervision, and assembly line approaches have been techniques that have successfully leveraged a launch with an existing business structure. Those models have had little success in the Information Age. For example, a need has risen to leverage supply and distribution with existing business models. Therefore, a new infrastructure must be created to develop and execute external proprietary strategies and capabilities.

The future of business is uncertain and being defined on a daily basis. Information Technology (IT) is rapidly changing with little remorse for those who fail to keep up. This technological environment will only be defined through the competition and cooperation of businesses involved. Just like valuable real estate, those who act quickly and decisively have the greatest impact and say so upon the development of the areas of purchase. So to is the IT environment. Only those who have the greatest 'insider' information and have the ability to act quickly will play a part in shaping and molding the future environment. In real estate there needs to be a heightened understanding of not only the property that exists, but the neighboring properties, community, city, and region to make a value based decision regarding whether to take stock in the investment. In IT the same type of knowledge must exist. A business needs to understand their capabilities, the capabilities of those around them that they do business with, the technology that support those capabilities, and proof of future maturation and value. Businesses must either take a leading role in developing and defining that environment or suffer the consequences of holding no stock.

Over time the entire business environment will be a technological environment. There is no pretending that it will disappear. An organization can change the degree of or speed into the environment, but can not ignore its presence. If a hurricane is approaching, a person can not stay in a place that has been safe for fifty years. That place has not yet seen a hurricane and there is no proof that it will remain safe. However, experience has shown that those who do know the "hurricane" is coming move to fast and are finding themselves in isolation.

This paper takes a detailed look at the steps necessary in taking a leadership position in the IT business environment. The paper exclusively introduces necessities for every organization to be successful. A corporation must develop an internal infrastructure, an external infrastructure, and use those infrastructures to become a learning organization.

\section{INTERNAL CAPABILITIES}

At all times an organization needs to know all roads available to them. They need to stay up to date on construction projects, new roads, and which roads will take them directly to their destination. If any unforeseen 'roadblock' occurs, an organization can act quickly and decisively rather than re-grouping and re-strategizing in a completely new way. Those responsible for the corporate vision need to understand the potential opportunities that 
exist in Information Technology. 'Understanding' is meant by acquiring knowledge regarding every opportunity that could result in the achievement of corporate goals. Then, and only then, can a business strategy be developed to support that vision. If the Information Systems (IS) strategy is built first and used solely upon the corporate vision, rather than a business strategy, any 'roadblock' in the rapidly changing IT environment will result in the corporate vision coming to a complete stop. The IS strategy must only be in full support of the Business strategy. Therefore, the Information System strategy can not be addressed until the Business strategy has been established.

This is due to technology, that is used to accomplish the IS strategy, not having the ability to exist as a means and an end. What does that mean? It means that technology can only be used to enhance or extend business operations and not define the operation itself. In other words, technology is pointless unless used by people. It can only be used to support physical processes that already exist through the actions of people. For example, a network is simply a structured process of communication. A technological network is a different means to accomplish the end of that communicative network. Processes such as this must be defined if a technological solution is possible. The business strategy is what defines and dictates all of those organizational processes. The question that must be answered forthright is what processes would the organization go through to accomplish the business strategy with only existing technology or no technology whatsoever? Those processes then must be mapped throughout the organization.

Common processes that exist, to name a few, are Change Management, Quality Assurance, Development, and Acquisition. All of these processes have individual objectives within the organization that are usually straightforward, but based upon requirements set by the corporate vision. What must be identified are the steps that must be taken to physically accomplish those objectives. Every step in every process must be defined. Accomplishing this is what is called standardization; simply, making the organizational processes visible. A great many companies have difficulty disciplining themselves in the hopes of achieving this standardization. For example, you may tell some one to walk. A step by step definition would tell that same person to raise the leg using the thigh muscle, push the foot forward using the calf muscle, lower the foot, and repeat the process with the other leg. Most companies assume such matters are common sense and neglect to define their processes on such a basic level. However, by standardizing processes the margin for error reduces significantly because the whole process is clearly defined. A person who normally walks backwards would walk backward when told to "walk". Through standardization that same person now understands how to "step" toward organizational goals.

A successful corporation has everyone "stepping" in the direction of those goals. Working cooperatively implies that every person has a role in the achievement of a desired outcome. The actions of those people are the processes. Therefore, since no person works alone, they're actions (processes) do not exist in isolation either. In light of this, all processes are dependent upon each other to communicate and work synchronously. These relationships between processes include steps of transition that must also be identified. Once this is accomplished, technology then can be introduced and tailored to support the processes. In other words, make the existing process more effective and efficient. The question that remains is what technologies will accomplish that goal.

The question of what technologies will accomplish the goal of effectiveness and efficiency is difficult question to answer. As previously stated, the IT environment is constantly changing. Determination of what technologies will best suit the organization will play an integral part in a company's success. Knowing what technology will be most resourceful in the future environment takes constant evaluation of trends within that environment. The main area of focus for such a determination needs to be on the effectiveness and efficiency in supporting the processes that exist. Some corporations leave this decision making up to the employees responsible for carrying out the processes because they know what would make they're job easier, but they usually will not have the organizational goals in mind. Other corporations may leave the choices up to the leaders of the organization, but they may not have the practical knowledge of day-to-day operations that the technology is meant to support. If the processes have been clearly defined and interconnected, like that which has been mentioned earlier, there should now exist the capability for data to flow up the processes. Decision makers can use this data to gain that understanding of operations that they were lacking. Now they are equipped to make value-based choices regarding technology. 
Based upon that flow of information other necessities will also be determined. A corporation can begin creating the structure. Many believe that structure can be created before technology is introduced because the structure is based upon the relationships of the processes. This is not so. Structure may limit the ability to adapt technology. As stated earlier, technology is useless unless able to be used by people. Therefore, it needs to grow simultaneously with the actions of those people. For example, technology may eliminate the need for data collection processes on a management level because it is being accumulated during the daily routine of employees. Due to this, the organizational structure would not need to incorporate a technological data collection responsibility for management. So given that example, in actuality the structure should already be $99 \%$ created. In other words, the organization of processes is what defines the structure. For instance, one entity within the structure is the lines of communication. These lines are created based upon the most effective means of processing data and distributing decisions. Simply, the structure of communication will be created based upon the natural flow of data up and decisions down the corporation.

This leads to an important benefit of the definition of processes that make up the structure of an organization. Islands of automation are prevented. These islands can easily occur if not carefully monitored. Different areas of the organization have independent projects. Because of the independent nature of their work, they easily make independent decisions. They can not be left to make decisions on their own or the old saying 'divide and conquer' will become a reality.

This is where defining the structure becomes vital. Those 'islands' need to become decision teams within the internal structure; in other words, steering committees. These committees process the data organized and prioritized by management and create information relevant to their needs. The type of data that they evaluate can range from daily records, audits, team meetings, quality assurance, and risk analysis. However, data can be collected from any relevant source. These committees take this information and develop executive summaries that provide information regarding current performance and requests to enhance that performance. Simply, these committees focus the priorities identified in the information and deliver it to the decision makers. In other words, these committees are an accumulation of managers who are in a position to coach and lead through evaluation, rather than spending time solely monitoring employees.

On a higher level, a steering committee for the whole organization also needs to be developed. Sitting on that committee should be such individuals as the CIO, CEO, representatives from each one of the other committees, and any other stakeholder. Suggestions regarding future actions can be evaluated against organizational goals, the benefits and risks to other areas of the organization, and effectiveness of implementing the action. This committee involves all stakeholders in the organization so that no one is isolated. More beneficial to the organization is the fact that these are brainstorming sessions. With complete information, these committees can 'leave no stone unturned' when it comes to possible opportunities for the success of the company.

As of now, in technology, the CIO is usually the one responsible for searching out, analyzing, and determining the best solution to an organization's technological needs. These committees relieve those responsibilities of the CIO and instead put him/her in an advisory position. Just as the CEO has the responsibility of guiding the business strategy, the CIO guides the information strategy. Both individuals work together, reporting to each other and a Board of directors. The CIO can begin concentrating on strategic decisions for the company rather than decisions regarding the day-to-day running of the technological end of the business. An Information Specialist can take on that role. This person can hold the responsibility of analyzing technology on the user level. They can push new applications up through the steering committee structure. Overall, each department can employ an Information Specialist for the implementation and maintenance of technology on that user level. Simply, all this consists of, is putting individuals in a clearly defined and manageable position that supports the processing of data into quality information for decision making.

The point of all of this internal structure is to effectively run the business. Running a business a majority of the time is a conservative effort. However, technology seems to get approached in a chaotic way. Why the different approach? It is because IT is invisible and does not talk back. All of the organization's blame for current problems or future hopes is put on the 'shoulders' of technology. To take the outlook that technology will become the savior of 
the organization is ridiculous. As stated previously, technology is only as good as the people who use it. Saying that, it is also not the root cause of all problems throughout an organization. When viewed from either one of these perspectives chaos regarding technology will ensue.

However, no corporation is perfect. They may find themselves at times caught up in this controversy over technology. When this happens organizations can not just simply reverse their strategy because they know that it is a direction that they have traveled safely. In other words, technology investments that run into the chaotic environment that exists, which is inevitable, should not be pulled back prematurely.

Therefore, a technological solution must be handled with patience and constantly evaluated. This is where other options must be understood. The corporation must keep in mind at all times that technology is supposed to support the running of the business in the new IT environment. A corporation needs to be content with the possibility that the payoffs may not come until further down the road or that the solution may lose value. In either case, contingency plans must always exist.

IT is not a game of solitaire or a foot race. A chess match is a better description. Those who move with strategic force mixed with patience and foresight will be the ones holding the most stock in the future technological environment. With standardization of processes in place along with a business strategy and structure, a corporation has implemented the ability to remain patient. However, the corporation at this time is not in a position to take a leading role in the development of the IT environment. They lack the foresight of opponent's moves, and the understanding of what the game board actually looks like.

So, the word patience is simply alluding to the fact that with the business running effectively and efficiently no longer does the concentration need to be put on running the business. Once processes are defined, an internal network set up, and technology being utilized a corporation can begin improving the business in the direction of strategic moves. To put it simply, a corporation can now make decisions based upon value rather than expense.

\section{EXTERNAL CAPABILITIES}

Once again, businesses do not exist in isolation. In the physical world processes are shared based upon an existing environment and the capabilities that it allows. The problem is, that the technological environment has not yet been defined. For the virtual world to exist effectively, businesses must work together to define what that world will consist of. In other words, an external infrastructure must be built that coordinates and communicates information among organizations.

The first value-based decision that needs to be made is how to position the corporation in the IT environment. Cooperation among partners is the only way, at this point, to gain a strong position. A great deal of corporations share similar processes and therefore can share common technologies. However, to understand this, data must be shared. The corporations need to understand each other's processes and technological needs. This is where a network of businesses, horizontally and vertically becomes extremely essential.

In a Network economy of scale, a community of firms uses a common infrastructure and capabilities to produce and distribute products and services faster, better, and cheaper. For example, in the physical world the amount of land available for new factories is common knowledge and businesses can make decisions based upon that concrete information. Networks need to provide the same type of concrete information. Network communities can only make adequate business decisions in such an environment.

One of two results will occur if this coordination does not take place. Either the organization can lead or be left behind. This risk of being left behind is too high if quality information does not exist regarding the external environment. Like in a hostile situation, people need to join forces to survive. Hiding may work in the short term to stay alive, only to find that in the long run, the world around you no longer holds a place for you. Together organizations need to create the environment. Just like people in the physical world have created streets, highways, 
telephone lines, and airplanes to keep us connected, the same sort of structure needs to be created in the IT environment.

However, having an external network does raise a concern regarding security. Corporations must pay a great deal of attention to this concern. An organization has introduced numerous entry and exit points to their internal operations. There needs to be someone guarding those "doors". In the physical world, threats to security are mostly known and guarded. However, in the virtual world, doors are being opened every day. Individuals have the ability to "blast" holes in the virtual wall with such things as viruses and worms. This is especially dangerous when operating in an e-commerce environment. Companies can be vulnerable to having their customers' personal information such as credit card and social security numbers stolen. When processes are simply enhanced or extended with a network, the customer should not take upon themselves the transitional consequences. The corporation must prepare on the front end for a seamless transition. The trust of the customer and the relationships held is important to keep in tact.

The seamless transition to an external structure is created in the same way as the internal structure had been previously. A business strategy needs to be developed. Processes need to be defined. Technology must then be used to support those processes. Finally, a structure needs to wrap it up with a nice little bow. However, this is not an isolated activity when dealing with the external environment. All businesses taking part in the creation of this network must participate from the business strategy clear through to the structure.

To set up such an external infrastructure, relationships need to exist. Ones built on trust and a shared vision. That vision can not be shared unless there is a strong commitment by all companies involved, and common business and ethical values exist. This is good advice for any partnership whether directed toward internal operations of a business or external like we are talking about here. Once the basis of the relationship has been set up, then business decision can begin to be made. Such as discussing whether the relationship will extend or enhance the capabilities of the corporation. If you were to extend you would partner with a stronger force. If the need was to enhance, a partner should be chosen that provides something that is lacking in the organization. Too many organizations handle this relationship building backwards. They go after who provides for the corporation's greatest needs of the moment. Then they try to force fit a friendship based upon a using relationship rather than a mutually improving one. An organization can find assurance in the strength of their IT investment only if the relationships are strong among multiple players.

This relationship building is extremely difficult in the light of creating global networks of businesses. IT has become a common infrastructure that has connected the world. Information can travel from one corner of the world to another in seconds. Organizations can now work globally around the clock to achieve their vision. However, the difficulty arises because of different cultural and business practices as well as regulations. A common language must be set up. For example, if one person speaks French and another speaks Russian, how do they communicate? This is a perfect example of why structure should be set up last. There is no point of organizing corporations if they can not even communicate. These global networks are where the "rubber hits the road" when developing the external environment. If the network is set up in the proper way, which has been stated previously, there should not be any devastating consequences occurring. However, if the external network is not strong, a global relationship will fall apart in the blink of an eye.

This is why many companies outsource their network control, putting the relationship management onto a third party. This third party's only concern is coordinating the stakeholders of the external network and therefore can accomplish the coordination more effectively and efficiently. Simply, corporations have someone act as an interpreter among the many relationships. Once again, this can only be done if all that are involved share a common vision, processes, technology, commitment, and values.

So the question is "how to become a leader within the environment if relationships are what guide the business in the external world". Are not most leaders in isolation? A look needs to be taken at what makes a person a good leader and then apply that to what traits a corporation needs to lead. A good leader is:

- Self-starter

- High standards
- Team builder

- Inspires others 
- Golden Rule

- Shares with stakeholders

- Integrity

- Reliability
- Builder of trust

- Not a lone wolf

- Patience and Urgency

- Superior learner

The company, as built so far, has coordinated the company and its partners as a team. If the organization has built relationships as suggested their integrity and reliability is in tact. Therefore, others should have the utmost trust in those relationships. Just by simply building those relationships, the organization has decided against approaching the IT environment as a lone wolf. The corporation has thus far made a strong move into the world of technology, but has done so patiently by making educated moves. The last trait remaining of a good leader is being a superior learner.

\section{LEARNING ORGANIZATION}

Due to the high risk of isolation in the IT world, business leaders must give equal weight to the external environment, which previously they have ignored, in making decisions. They have avoided collecting adequate information from external sources because decisions are tough to make in a rapidly changing environment. Success for launches of new business opportunities needs to become dependant upon balancing internal infrastructures with external. Simply, the reasoning behind creating these networks in the first place is to reduce change because traditional performance measures simply don't work in constant change. Informed decisions only come in a reusable and consistent environment that offers historically compared data. Within that consistent network, the business leaders can once again rely on their traditional measures.

All business models have three keys to performance. These keys are strategy, capabilities, and benefits. First and foremost, leadership must define a business concept. This concept outlines the opportunity or strategy of a business. This opportunity is defined through market assessment, product/service offerings and pricing, competitive and industry dynamics, and plans for evolution and growth. With access to the external environment these assessments are now grounded in reality. The company can begin analyzing what activities hold the most value for a competitive advantage. This is essential because defining strategy and opportunity is the cornerstone of any future decisions. The concept becomes the frame for the assumptions used to forecast revenues. All decisions here on out will aid the fulfillment of that opportunity/strategy.

Such strategy decisions revolve around evaluating the impact of IT on operations and strategy. This evaluation will determine what competitive advantage a corporation will hold upon implementing a technological solution. Based upon understanding which technological solution will have the greatest impact a prioritization of IT investments can take place. Such strategies such as to buy or make, or to coordinate or own can begin to be evaluated. Of course other concerns such as environmental characteristics, cost, flexibility, and opportunity cost need to be analyzed. Upon proper evaluation and definition of strategy, a corporation can begin concentrating on implementing that strategy.

Upon clear definition of the business concept, capabilities must be identified or established in support of the strategy. Capabilities identify the resources required to exploit the opportunity and execute the strategy. These capabilities are dependent upon resource requirements and availability, as well as the organization and infrastructures ability to efficiently and effectively execute strategy. This is where the network community information is essential. The defined processes allow for visibility of all capabilities. Simply, the common platform for external and internal infrastructures transfers relevant and accurate data to decision makers that can be used to evaluate an organization's capabilities.

Also, if that supporting infrastructure exists, then operating and innovating capabilities can be established. In other words core processes of converting inputs to outputs, across boundaries, to create value can be identified, measured, and manipulated. The historical data gathered from these core processes during operation allow for managing and learning capabilities. Accurate data from clearly defined processes allows the development of higherlevel processes for plans, budgets, and performance monitoring. If there is an organizational design that supports this 
flow of information the door swings open for information knowledge management. With all the correct information filtering from operations to management and up to leadership, decisions can be made. Leading and engaging in capabilities then becomes a factor. Basically, the connection between leadership across boundaries of human resource management systems, alliance and partnership management, and customer/supplier relationship management systems decisions become as concrete as a parking lot. When that exists, a corporation knows the full potential of its capabilities.

When opportunity and capabilities are connected and based upon sound decision making, businesses can expect certain benefits. First, internally and externally, a business can expect to increase performance, functionality, and flexibility. Secondly, efficiency and quality should improve in commerce. Next, due to the reusability of historical information more knowledgeable workers should exist across the whole organization. Finally, in such an environment, motivation, loyalty, and trust will increase while retaining the most talented workers, loyal customers, and satisfied investors. However, benefits are invisible unless measured by defined standards. On the most basic level opportunities are measured by revenues and business capabilities are measured by costs.

Due to this, without the benefits experienced through disciplined standardization of processes, strong relationships, and a learning organization revenues and costs could not be adequately measured in an IT environment because the opportunities and capabilities are not clearly understood and defined.

This leads to the third key to business performance, benefits. Benefits can be identified by increased capabilities, new opportunities, or simply financial returns. Simply, this is measuring the benefits accumulated from investment. As stated previously, these benefits may not appear instantly. To understand these benefits constant evaluation must occur. These evaluations are based upon the assumed forecasted revenues established when the strategy was implemented. Measuring these benefits is reliant upon the discipline of the stakeholders, for it is not due to lack of data if the internal and external infrastructures are sound.

All of these together drive financial performance so true analysis only happens when measuring these three keys. The measuring results in a value proposition that identifies the expected benefits returned to all stakeholders and the results executives expect to achieve. To put it simply, Value $=$ Concept + Capabilities + Benefits. This evaluation of value is a traditional model that only holds validity if all previous steps have been accomplished. Without the complete transition to an IT environment, businesses are gambling with their future.

\section{CONCLUSION}

A corporation needs to be a learning organization to have the ability to strategically position the corporation into a leadership position. For example, some companies have been successful in developing the ability to make strong moves in IT because they spend $1 / 3$ on running their business and $2 / 3$ on improving their business, not because they fill the greatest niche for a short amount of time. This paper has revolved around organizations needing to put themselves in this type of position.

In organizations, success is dependent upon quality decision-making. Those who are responsible for those decisions guide the future of any organization. They develop the vision for the organization and weigh the capabilities of implementing strategy in the hopes of fulfilled opportunity. A realistic vision and strategy, as well as confidence in the capability to carry it out, relies heavily on understanding the opportunity that exists. Understanding comes only through quality information. Information does not exist without detailed data. Organizations talk about the need for informed decision-making, but often fall short of accomplishing those decisions. The organization needs to understand the environment in which they want to see their vision realized, as well as understand the capabilities they have in fulfilling that vision.

Value will come to a company when they are able to leverage this existing internal infrastructure, the external (networked) infrastructure, and the launch of a new product or service. If this balance exists, a corporation only needs to manage the small bumps by establishing a common set of performance measures that link strategy to execution to results. A corporation then, and only then, can begin taking a lead role in shaping the environment. 


\section{REFERENCES}

1. Applegate, Linda M., Robert D. Austin, and F. Warren McFarlan, Corporate Information Strategy and Management, Irwin Publisher, Sixth Edition.

2. Senge, Peter, Art Kleiner, Charlotte Roberts, Richard Ross, and Bryan Smith, The Fifth Discipline Fieldbook, Doubleday Publisher, New York.

3. Ulferts, Gregory, “A Successful Information Systems Organization”, Working Paper.

\section{NOTES}

